\title{
DESIGN SOCIAL: DESENVOLVIMENTO DE MATERIAL DIDÁTICO PARA EDUCAÇÃO BÁSICA
}

\author{
Ana Veronica Pazmino \\ Universidade Federal de Santa Catarina \\ anaverpw@gmail.com
}

\begin{abstract}
Resumo
O trabalho mostra o resultado do projeto de extensão UFSC - 2018 "Design e Educação: objetos e materiais didáticos voltados para a educação básica", em que houve a articulação da ação de extensão e o ensino com as disciplinas: metodologia de projeto EGR7112; Seminários de design social EGR7118; EGR7196; EGR7197 de PCC1 e PCC2 Projeto de conclusão de curso nos semestres de 2018/1 e 2018/2. O objetivo da ação de extensão foi: propor soluções por meio do design para contribuir com a ação educativa na Rede Municipal de Ensino de Florianópolis. Na busca de possibilitar a ação social os objetivos específicos foram: levantar informações sobre as necessidades de professores em creches e ou préescolas; desenvolver soluções para problemas identificados pelos professores e na escola durante a pesquisa; desenvolver materiais e entregar nas escolas. A metodologia adotada para o desenvolvimento do projeto foi o Design Thinking. Em um ano o projeto teve 20 materiais didáticos (jogos e livros) para crianças, adolescentes e professores de 16 escolas da rede Municipal de Florianópolis.

Palavras-chave: Design Social. Design e Educação. Design de Produto e Gráfico.
\end{abstract}

\section{SOCIAL DESIGN: TEACHING OBJECTS AND MATERIALS BACK TO EDUCATION}

\begin{abstract}
The paper shows the result of the extension project UFSC - 2018 "Design and Education: objects and teaching materials focused on basic education" in which there was the articulation of extension action and teaching with the subjects: project methodology EGR7112; Social Design Seminars EGR7118; EGR7196 and EGR7197 of PCC1 and PCC2 Course completion project for the 2018/1 and 2018/2 semesters. The objective of the extension action was: to propose solutions through design to contribute to the educational action in the Florianópolis Municipal Education Network. In order to enable social action, the specific objectives were: To gather information about the needs of teachers in day care centers and / or preschools; develop solutions to problems identified by teachers and at school during research; develop materials and deliver to schools. The methodology adopted for the development of the project was Design Thinking. In one year the project had 20 teaching materials (games and books) for children, adolescents and teachers from 16 schools of Florianópolis Municipal network.
\end{abstract}

Keywords: Social Design. Design and Education. Product Design and Graphics.

\section{DISEÑO SOCIAL: OBJETOS Y MATERIALES DIDACTICOS PARA LA EDUCACION}

\section{Resumen}

El trabajo muestra el resultado del proyecto de extensión UFSC - 2018 "Diseño y Educación: objetos y materiales didácticos orientados a la educación básica" en que hubo la articulación de la extensión y la enseñanza con las disciplinas: metodología de proyecto EGR7112; Seminarios de diseño social EGR7118; EGR7196; EGR7197 de PCC1 y PCC2 Proyecto de conclusión de curso. El objetivo de la acción de extensión fue: proponer soluciones por medio del diseño para contribuir con la acción educativa en la Red Municipal de Enseñanza de Florianópolis. Para realizar la acción social los objetivos específicos fueron: Levantar informaciones sobre las necesidades de profesores en guarderías y escuelas; desarrollar soluciones para problemas identificados por los profesores y la escuela durante la investigación; desarrollar materiales didácticos, aplicar y entregar en las escuelas. La metodología adoptada para el desarrollo del proyecto fue el diseño Thinking. En un año el proyecto tuvo 20 materiales didácticos (juegos e libros) para niños, adolescentes y profesores de 16 escuelas Municipales de Florianópolis.

Palabras clave: Diseño Social. Diseño y Educación. Diseño de Producto y Gráfico. 


\section{INTRODUÇÃO}

Para James Heckman, pesquisador e prêmio Nobel de 2000, na fase inicial de uma criança o cérebro se desenvolve em velocidade frenética e tem enorme poder de absorção, como uma esponja maleável. As primeiras impressões e experiências na vida preparam o terreno sobre o qual o conhecimento e as emoções vão se desenvolver mais tarde. Se essa base for frágil, as oportunidades de sucesso cairão; se ela for sólida, vão disparar na mesma proporção. Por isso, ele defende estímulos desde muito cedo.

Heckman criou métodos científicos para avaliar a eficácia de programas sociais e vem se dedicando aos estudos sobre a primeira infância - para ele, um divisor de águas.

Até os seis anos, a criança aprende em ritmo espantoso, e isso será valioso para toda a vida. Infelizmente, esta é uma fase que costuma ser negligenciada - famílias pobres não recebem orientação básica sobre como enfrentar o desafio de criar um bebê, faltam boas creches e préescolas.

Sendo assim, o presente artigo aborda o resultado de um projeto de extensão que apresenta soluções de design de material didático voltado a creches e pré-escolas para que as crianças aproveitem a capacidade de se beneficiar do ambiente. Quanto mais uma criança fica para trás, mais dificuldade terá para preencher as lacunas do princípio.

Abordando a história do Design for Change DFC (Dfcworld, 2017), este surgiu no ano de 2001 quando a professora e designer Kiran Bir Sethi fundou a Riverside School com o intuito de capacitar pessoas para resolver desafios como falta de educação, discriminação, problemas de saúde, cidades e outros. No ano de 2009, na mesma cidade que fundou a Riverside School, Kiran, deu-se início o projeto Design For Change. O Design for Change (DFC Índia, 2009) é o maior movimento global para crianças aplicarem mudanças em suas próprias comunidades. Esta abordagem foi desenvolvida com o intuito de promover mudanças na vida das pessoas pelo empoderamento das crianças na educação. O Design for Change consiste em quatro etapas e pode se apoiar em diferentes métodos.

No ano de 2011, foi lançado o livro "I can", que conta as histórias de transformação através do DFC, e, no ano de 2012 o projeto recebeu o prêmio de inovação pela Rockefeller Foundation. Em 2014, o DFC foi introduzido no currículo escolar de forma piloto, em 64 escolas da Índia, porém já se encontrava em mais de 30 países pelo mundo, um deles o Brasil, através do projeto criativos da escola.

A busca por soluções vem sendo transformada pela educação, por isso a importância de projetos como este, que tem como critérios protagonismo, empatia, criatividade e o trabalho em 
equipe. O DFC apresenta a educação como protagonista-chave dessas transformações, podendo levar a soluções de problemas em nossas comunidades.

Além do DFC, outro tema tratado no projeto de extensão foi o design social, que tem uma abordagem de aproximação às necessidades reais da sociedade, visando atender as comunidades ou grupos sociais que não são contemplados pelo mercado e sofrem o descaso do poder público. Ele abrange pessoas de baixa renda, com deficiências, idosos, e todo tipo de individuo ou comunidade que tem necessidades específicas não atendidas por ser um grupo reduzido e/ou de baixo poder aquisitivo. O designer social precisa de uma atitude generosa, empática e criativa para atender necessidades com soluções de alta qualidade e custo baixo. É importante, que no ensino, os alunos tenham contato com a prática social da profissão.

O projeto de extensão "Design e Educação: objetos e materiais didáticos voltados para a educação básica" teve como objetivo geral: propor soluções por meio do design, para contribuir com a qualidade da ação educativa na Rede Municipal de Ensino de Florianópolis, e, como objetivos específicos:

- Levantar informações sobre as necessidades de professores em creches, pré-escolas, ensino fundamental;

- Desenvolver de soluções para problemas identificadas nas diretrizes pedagógicas e dos apontados pelos professores e escola durante a pesquisa;

- Desenvolver materiais; e

- Entregar os objetos e aplicá-los nas escolas.

\section{MATERIAIS E MÉTODOS}

A metodologia adotada para o desenvolvimento do projeto foi o Design Thinking, onde o ser humano é colocado em primeiro lugar com ênfase em suas necessidades fundamentais. " $\mathrm{O}$ design thinking se baseia em nossa capacidade de ser intuitivo, reconhecer padrões, desenvolver ideias que tenham um significado emocional além do funcional”. (BROWN, 2009).

É um método exploratório, sem um roteiro sequencial de passos ordenados, há apenas pontos de partidas e pontos de referências ao longo do trajeto. Para Brown (2009) a equipe de design deveria transitar por estes três espaços ao longo do projeto: um espaço de "Inspiração" ou "Imersão" que é o problema ou a oportunidade que motiva a busca por soluções; pela "Idealização" ou "Ideação" que é o processo de gerar, desenvolver e testar ideias; e o espaço de "Implementação" ou "Prototipação" que seria o caminho que vai do designer ou equipe de design ao mercado. Foi considerado o levantamento de informações em creches, pré-escolas, 
ensino básico e lugares onde o sistema público carece de materiais de auxílio ao ensino. Os públicos-alvo foram crianças, adolescentes e professores de creches, pré-escolas, ensino fundamental, abrigos, APAE e espaços socioeducativos de Florianópolis. A pesquisa de campo foi por meio de registros fotográficos e questionários aplicados a professores, e os resultados são: objetos e ações que as escolas, crianças e professores receberam para incentivar as crianças e adolescentes e melhorar o espaço de aprendizagem.

O projeto contou com duas bolsas do programa probolsas UFSC e houve articulação com o ensino nas disciplinas de metodologia de projeto EGR7112 para o desenvolvimento de soluções, na disciplina de Seminários de design social EGR7118 para escrita de artigos das ações e com as disciplinas EGR7196 e EGR7197 de PCC1 e PCC2 projeto de conclusão de curso em que duas alunas realizaram as pesquisas e desenvolvimento de soluções como projeto final. $\mathrm{O}$ vínculo com o ensino teve como resultado um maior número de escolas atendidas. O projeto teve 20 ações realizadas em 16 escolas com materiais didáticos para crianças, adolescentes e professores. O principal objetivo do trabalho dos bolsistas foi identificar as necessidades dos professores e alunos das escolas listadas no item resultados, e auxiliar os alunos das disciplinas EGR7112 do curso de design a desenvolver e materializar as soluções.

\section{DESENVOLVIMENTO}

A visita a diversos ambientes escolares foi demorada devido à necessidade de ter autorização da Secretaria Municipal de Educação: Gerência de Educação Continuada de Florianópolis, nesses casos a explicação do projeto devia ser enviada e a Gerência e após análise, enviava uma carta para que os alunos pudessem entrar nas escolas. Os resultados dos projetos que receberam a carta da Gerência foram entregues nas escolas e os relatórios de projeto enviados a Gerência.

$\mathrm{Na}$ fase de imersão do projeto, para auxiliar a identificar as necessidades específicas foram utilizados métodos de design como: pesquisa do usuário por meio de questionários, entrevistas, observações, mapa mental ou conceitual, lista de necessidades. Posteriormente foi feita uma seleção das necessidades, análise sincrônica de produtos concorrentes e similares, lista de verificação e definir o que poderia ser desenvolvido de forma que seja de baixo custo, viável e de boa qualidade (durável).

A figura 1 mostra um mapa mental que sintetiza a pesquisa geral documental que identificou os maiores problemas na escola pública. A mesma ação de pesquisa e síntese em mapa mental e/ou conceitual foi repetida pelos 20 projetos. 


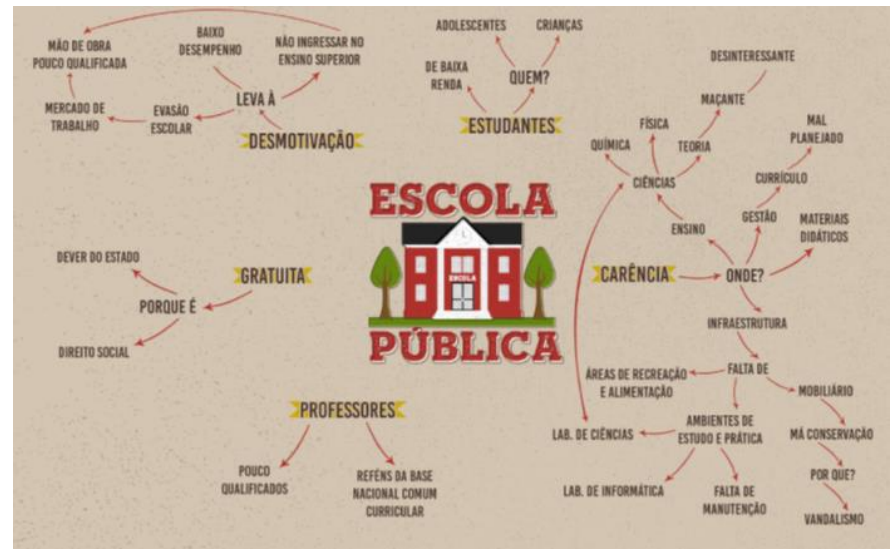

Figura 1 - Mapa mental

Fonte: KUMAGAI e TOMAZZIA (2017)

Após a pesquisa geral e entendimento da problemática do ensino público, foram visitadas várias escolas. Aqui são listadas 16 escolas e/ou ambientes, a escolha dos lugares foi dos alunos, em alguns casos por proximidade do lugar onde moram, já estudaram nessa escola, ou conhecem alguém que trabalha nela, as escolas visitadas foram:

- Escola João Francisco Garcez no bairro Costa de Lagoa

- EBB Júlio da Costa Neves

- Escola Rosinha Campos

- Creche Nossa Senhora Aparecida

- E.B Adotiva Liberato Valentim

- EB Vitor Miguel de Souza (carta da Gerência)

- APAE (Associação de pais e Amigos dos Excepcionais)

- Creche São Francisco de Assis

- Escola Básica Municipal Henrique Veras, situada no bairro da Lagoa da Conceição

- Abrigo Casa Lar AMAR I em São José, Santa Catarina

- Centro de atendimento socioeducativo de Florianópolis

- NDI Núcleo de Desenvolvimento Infantil UFSC

- Colégio Primeiros Degraus e São José, Santa Catarina

- Escola de Educação Básica Vitório Anacleto Cardoso, de Gaspar/SC

- Escola de Educação Básica João Widemann, de Blumenau/SC.

- CEI Frei Ático (são Pedro de Alcântara)

A pesquisa esteve envolvida nos primeiros meses do projeto em que o levantamento sobre material didático, currículo escolar, didática na escola e pré-escola e em ambientes como APAE que deram o suporte teórico para o desenvolvimento de material didático adequado. A extensão aconteceu na imersão dos alunos do curso para entender os problemas e necessidades dos professores e alunos em encontros pré-agendados nas creches e escolas escolhidas.

A figura 2 mostra infográficos que sintetizam os resultados das pesquisas nas escolas e direcionam as necessidades que as crianças e professores manifestaram. Na figura 2 uma pesquisa 
direciona para um material para auxiliar no ensino e aprendizagem de química e história e outra de matemática.

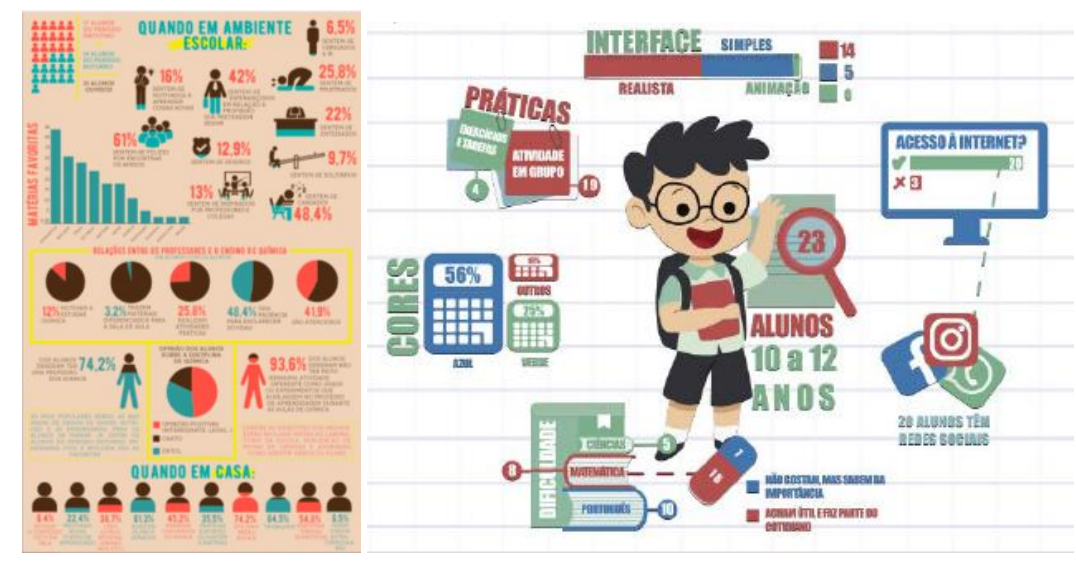

Figura 2 - Infográficos

Fonte: KUMAGAI e TOMAZZIA (2017) e SOUZA e WERNER (2017)

Cabe salientar que os resultados foram produzidos devido ao curso de Design de Produto da UFSC ter a competência de desenvolver produtos (jogos, objetos) e o curso de Design o material gráfico de auxílio para o processo de aprendizagem. Os cursos de Design contam com o Laboratório Pronto 3D de Prototipagem e Novas Tecnologias, vinculado ao Centro de Comunicação e Expressão CCE/UFSC, foi criado em 2013, com o objetivo de atender cursos do meio acadêmico, nas áreas de ensino, pesquisa e extensão, e sociedade em geral. Suas atividades abrangem áreas que envolvem a criação, desenvolvimento e produção de produtos, protótipos, maquetes, utilizando tecnologias, ferramentas, métodos, auxílio nas diferentes etapas do processo, transformando ideias em projeto real, físico.

Para a construção do material didático e o curso também conta com laboratórios e softwares gráficos para o desenvolvimento de material gráfico, embalagens, manuais e mídias digitais.

\section{RESULTADOS E ANÁLISES}

Os resultados do projeto são objetos e materiais gráficos para escolas e ambientes educacionais atendendo as demandas que os professores e alunos manifestaram. Cada material tem o nome do aluno que desenvolveu e as características da solução. 


\section{Recicleduc}

O Jogo Recicleduc foi feito para a Creche Nossa Senhora Aparecida e objetiva ensinar o correto destino dos resíduos e promover a reciclagem de forma lúdica e divertida. O resultado é um painel com figuras imantadas em que os alunos devem colocar os resíduos nos lixeiros adequados, tem também um manual para que o professor possa passar para os alunos informações sobre a reciclagem. A figura 3 mostra a aplicação na Creche e o manual do jogo.
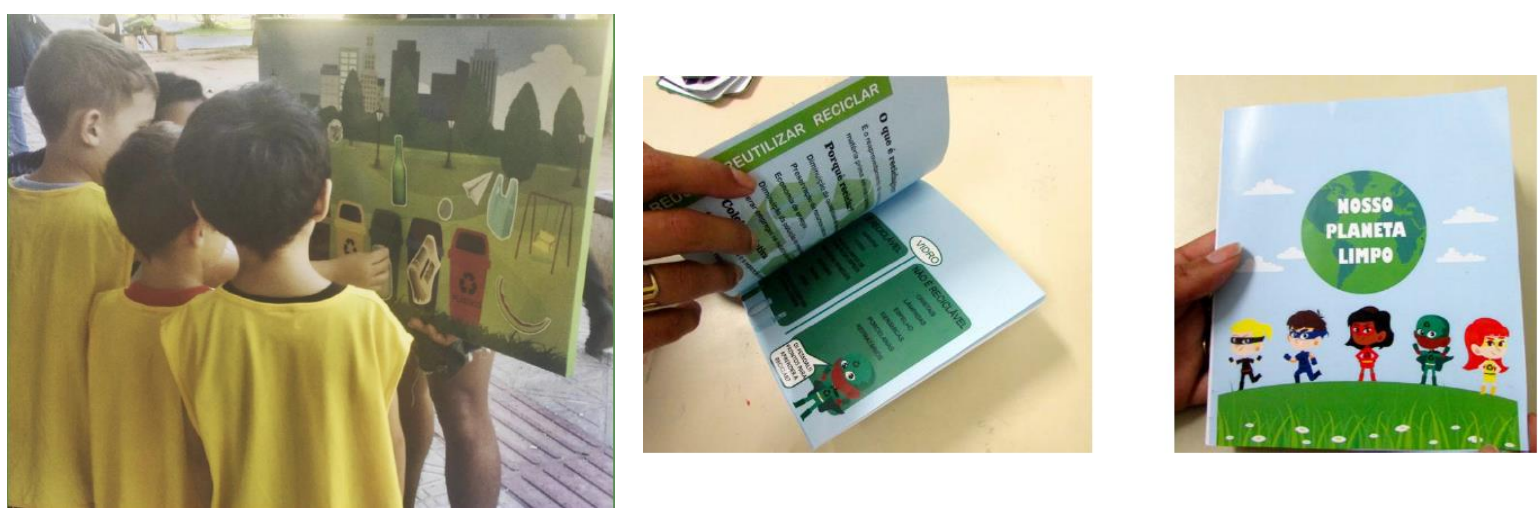

Figura 3 - Aplicação do jogo Recicleduc na Creche Nossa Senhora Aparecida Fonte: BELMONTE; MARTINS (2017)

\section{Geo jogo}

O Geo Jogo foi feito para a escola EBB Júlio da Costa Neves para alunos do $6^{\circ}$ ano com conteúdos adequados sobre geografia. A professora da escola participou ativamente do conteúdo que deveria ter o jogo e aprovou a dinâmica. A figura 4 mostra o jogo de baralho de geografia.
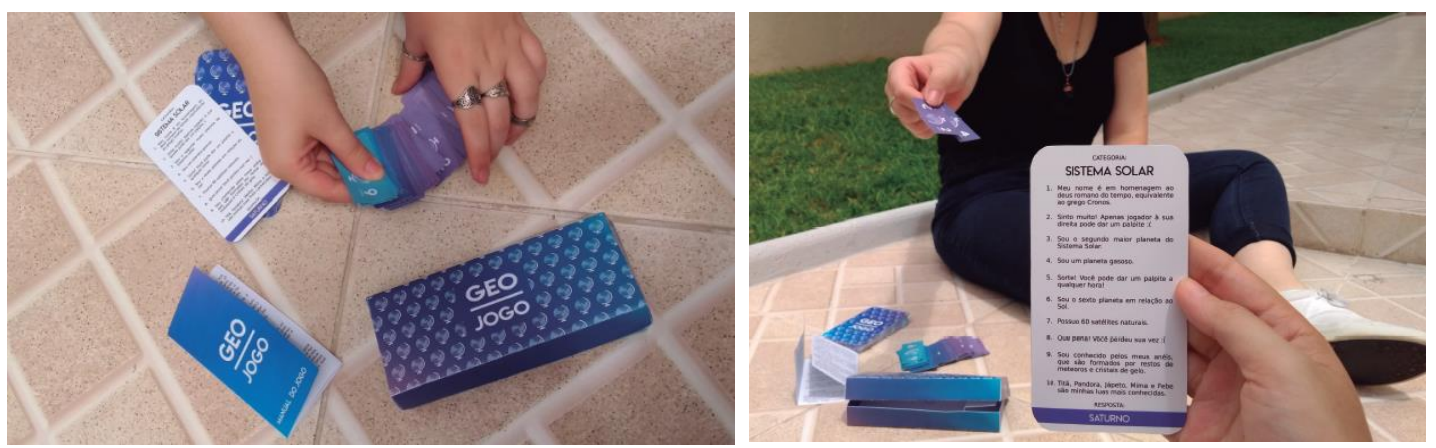

Figura $4-$ GeoJogo

Fonte: WINER e SELL (2017)

\section{Fauna maluca}

O jogo fauna maluca foi feito para a Escola Rosinha Campos para crianças de 6 anos. O objetivo é estimular a criatividade por meio de um baralho que permita que as crianças criem animais aleatórios combinando a cabeça com o tronco, estimulando o lado direito do cérebro 
evitando o lógico e óbvio. Assim a criança pode ter um animal com cabeça de porco e corpo de pinguim, ou um elefante com corpo de vaca. A figura 5 mostra o jogo.

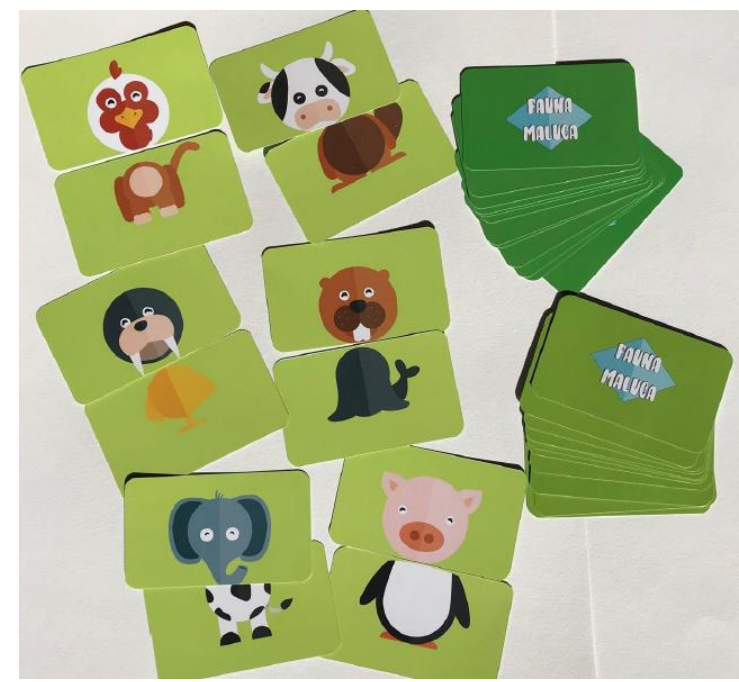

Figura 5 - Fauna Maluca Fonte: OSORIO (2017)

\section{O contador de histórias}

O contador de histórias é uma estante multifuncional de livros para crianças de 7 a 10 anos que além de guardar livros serve como cenário para contar histórias em que os personagens podem ser colados ou desenhados num painel. Por ser um mobiliário o modelo final foi feito em escala 1:5, mas, o desenho técnico está pronto, podendo ser cortado e montado se a escola quiser o móvel. A figura 6 mostra o modelo em escala 1:5. O modelo serve também como brinquedo.

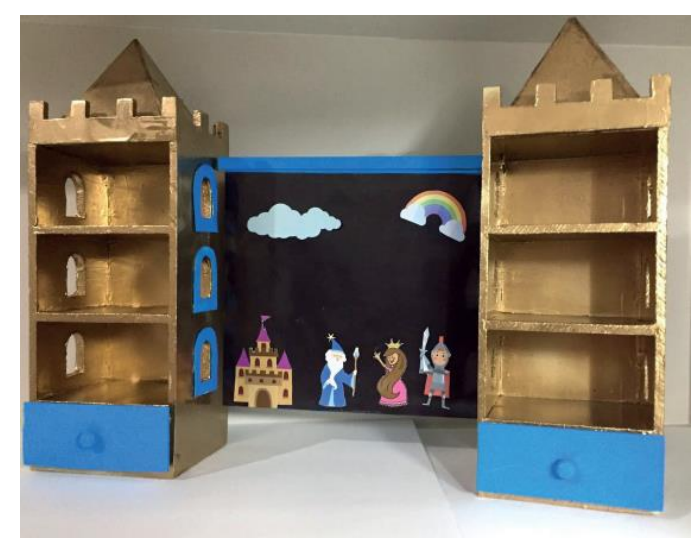

Figura 6 - contador de histórias Franco e Guerra (2017)

\section{Painéis interativos}

Os painéis interativos foram feitos para a Escola Vitor Miguel de Souza, os 5 painéis foram fixados nas paredes da sala de aula com a ajuda da professora, segundo ela cada painel devia estar em um local específico, pois isso ajudaria a dinâmica da turma. 
Algumas crianças testaram os painéis, e o resultado foi gratificante, os alunos gostaram e se mostraram interessados pelas atividades. A figura 7 mostra o uso dos painéis na escola.

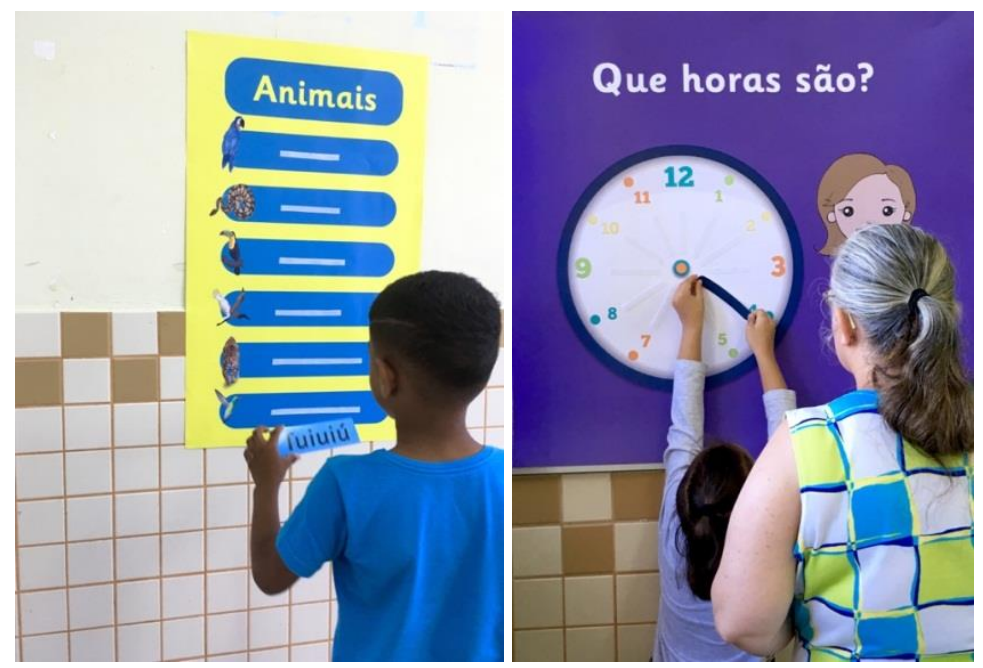

Figura 7 - Painéis interativos Fonte: PAIM; JESUS (2017)

\section{LUME Método Criativo Escolar}

Lume Método Criativo Escolar foi feito com base na pesquisa na Escola João Francisco Garcez para crianças de 6 a 10 anos para que estes possam criar soluções em relação aos problemas que eles encontram na escola, na casa ou no ambiente externo. O objetivo do método é que as crianças junto com o professor sigam passos e métodos de design para solucionar problemas de forma criativa e em equipe. A Figura 8 mostra o método de cartas Lume.

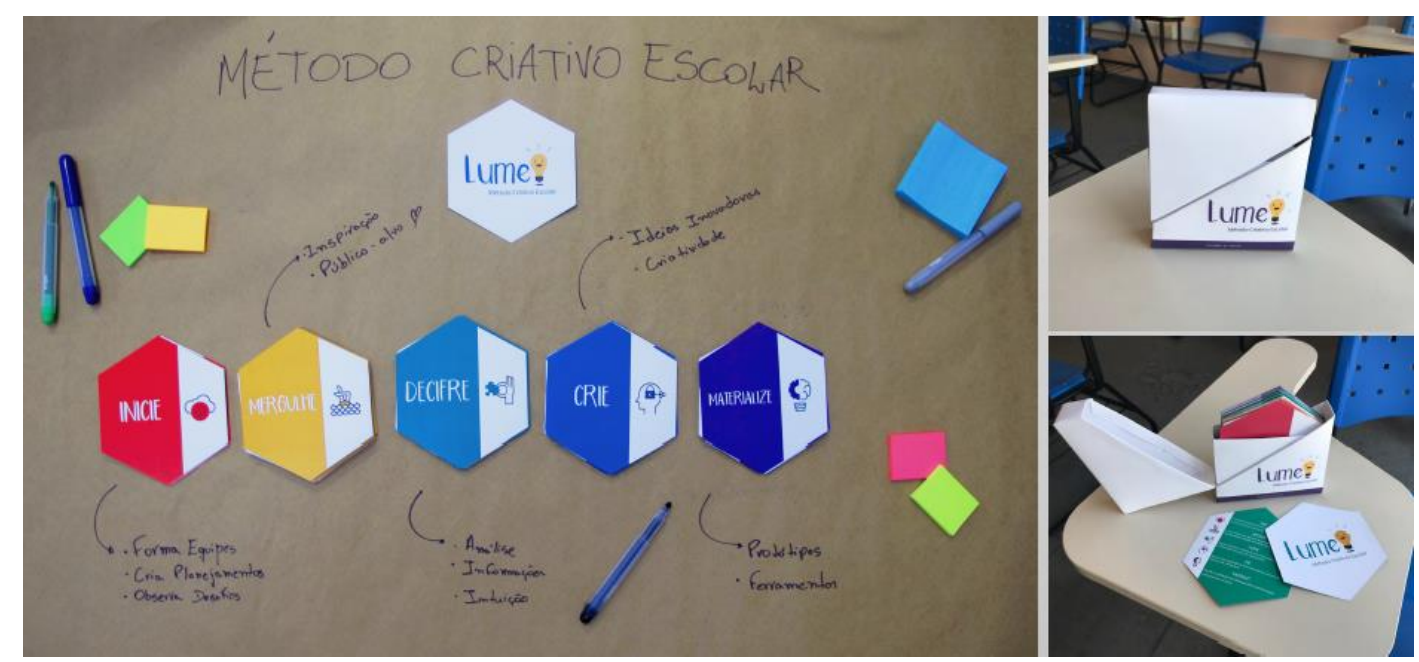

Figura 8 - Lume Método criativo escolar Fonte: KARKLING; CHICARELLI (2017) 


\section{Chemistory}

Jogo de química e história foi desenvolvido para a EBB Júlio da Costa Neves, trata-se de um jogo de tabuleiro que representa laboratórios de seis países, com cientistas famosos cuja história é contada nas cartas de história; também possui cartas de desafio de química geral e orgânica. O jogo possui peças para formar estruturas de cadeias orgânicas. A figura 9 mostra o jogo.
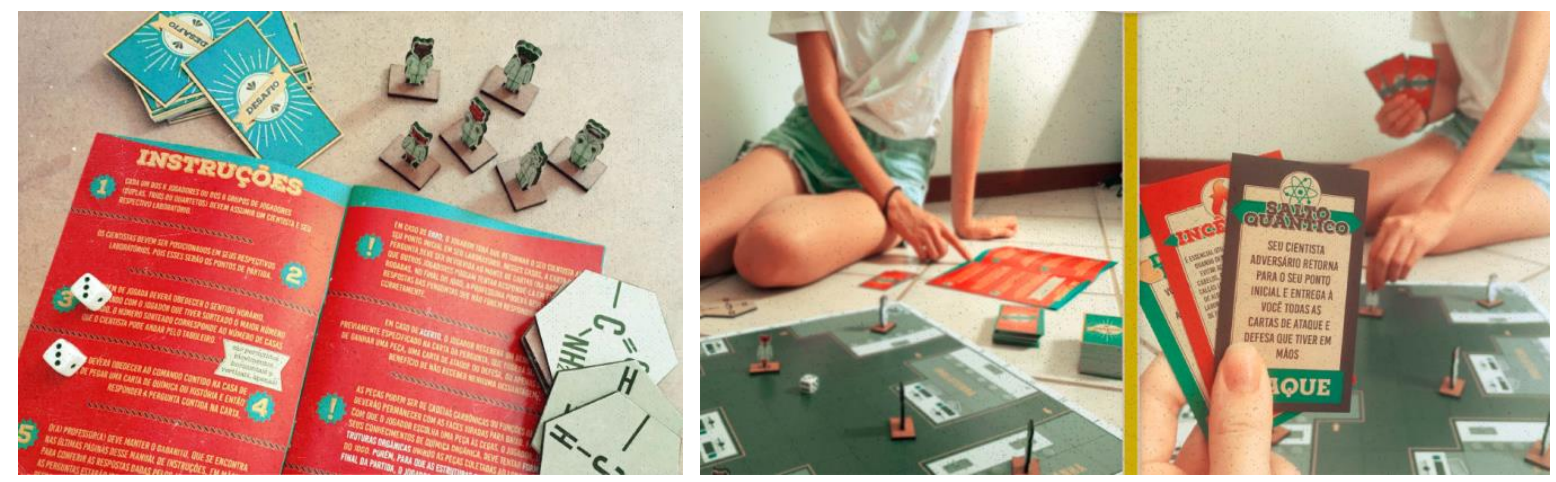

Figura 9 - Chemistory

Fonte: KUMAGAI; TOMAZZIA (2017)

\section{Cidade Matemática}

O jogo cidade matemática é um auxílio didático para o professor e para o aluno para responder e solucionar problemas em conjunto (grupo de 4 pessoas). Ao final do jogo, dependendo das respostas, a cidade pode ficar limpa ou se tornar um caos. As pesquisas foram feitas em duas escolas: EBB Vitório Anacleto Cardoso, de Gaspar/SC e Escola de Educação Básica João Widemann, de Blumenau/SC. A figura 10 mostra o jogo com crianças de 10 e 12 anos que aprovaram a dinâmica. As perguntas do jogo foram aprovadas por professores de matemática.
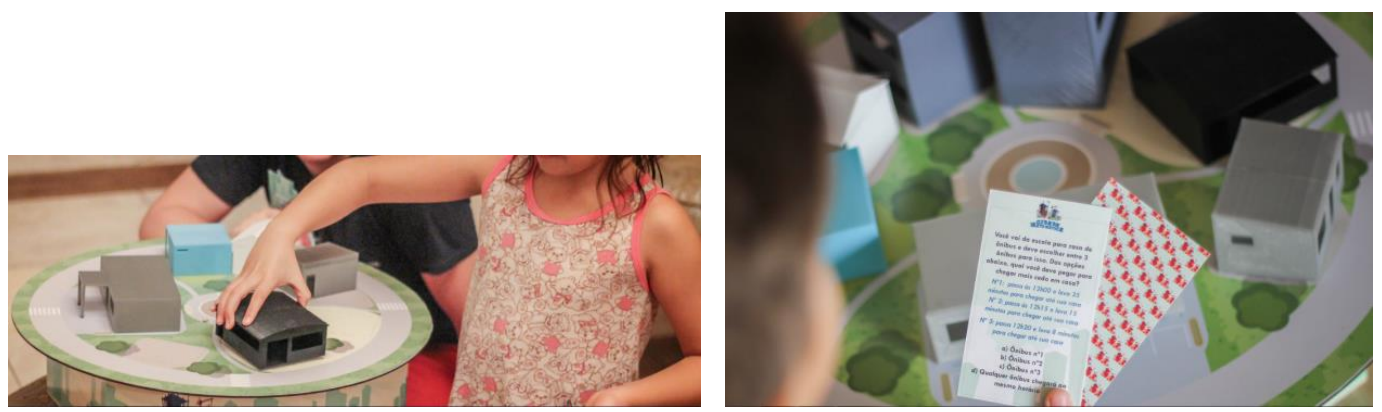

Figura 10 - Cidade matemática Fonte: SOUZA; WERNER (2017)

\section{Banco-Baú}

O BANCO-BAÚ foi desenvolvido para crianças de 6 a 12 anos, para a Escola Desdobrada Municipal João Francisco Garcez. Esta demanda surgiu da necessidade de bancos para a quadra em que os alunos jogam as mochilas no chão. Assim, no baú do banco podem ser 
guardadas as mochilas e servir de bancos para sentar. A figura 11 mostra o modelo em escala 1:5. Assim que a escola tiver verba o banco poderá ser confeccionado no Laboratório PRONTO 3D da UFSC. Já que foi projetado para ser cortado em CNC e montado por meio de encaixes.
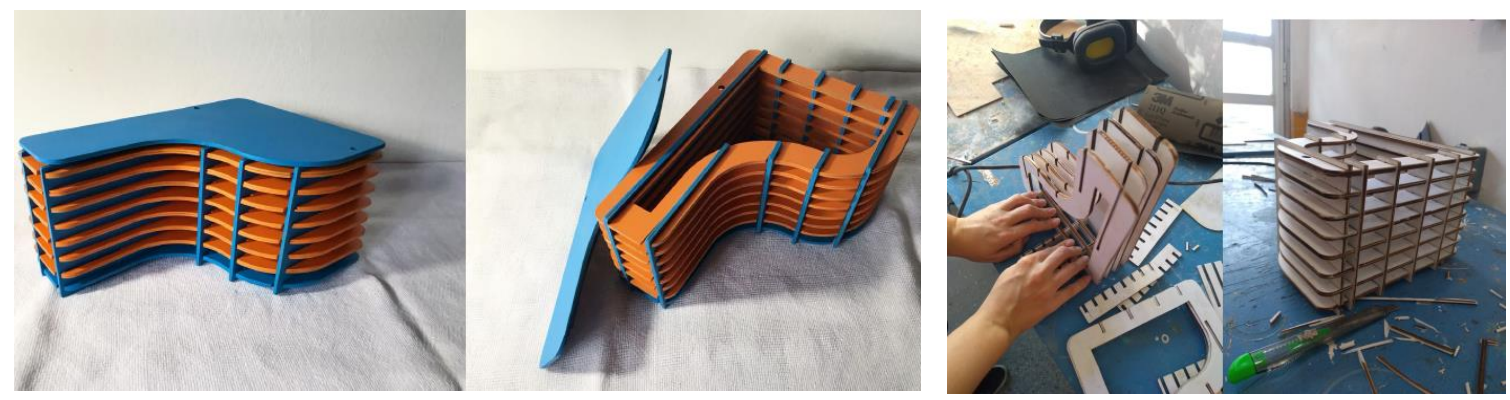

Figura 11 - Banco-Baú em escala 1:5 Fonte: TILLMANN; ECKSCHMIDT (2017)

\section{Kit pedagógico para TEA (Transtorno do Espectro Autista)}

O Kit foi desenvolvido para a APAE Florianópolis para auxiliar no desenvolvimento das habilidades motoras finas de crianças com TEA. O material trabalha a sensibilidade tátil, o entendimento do abstrato e a diferenciação de pesos. A figura 12 mostra o conjunto de pesos em formato de animais (eles têm sacos de areia). Também uma criança brincando com a abelha como fantoche.

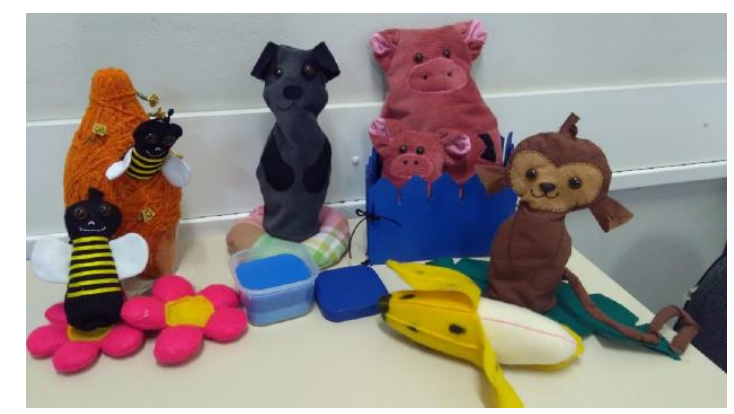

Figura 12 - Kit pedagógico para TEA Fonte: SAVALL; ALVES (2018)

Um dos objetivos é que as crianças com TEA desenvolvam o tato, dessa forma, os animais tem dois lados que podem ser alterados virando pelo avesso. O porco e tem dois tamanho e texturas diferentes pelo avesso.

\section{MOVIMENTE}

O Movimente é um jogo de tabuleiro para o abrigo Casa Lar AMAR em São JoséFlorianópolis. Trata-se de um jogo divertido para desenvolver a criatividade e motivação por 
meio de ações que tem de ser realizadas pela interação das crianças e adolescentes. A figura 13 mostra o tabuleiro e as cartas.
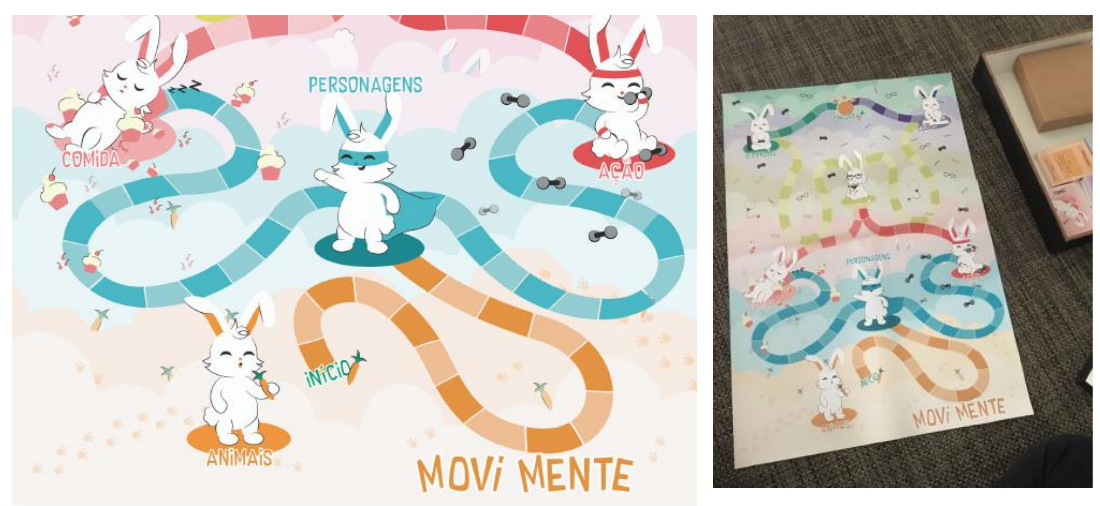

Figura 13 - Movimente

Fonte: SUPTITZ; MEDINA (2018)

\section{Coleção Meu Mundo no Banheiro}

Três livros que auxiliam as crianças do espectro autista a superarem suas dificuldades no banheiro de modo simples e informacional. $O$ material foi desenvolvido para a APAE Florianópolis. A figura 14 mostra os livrinhos.

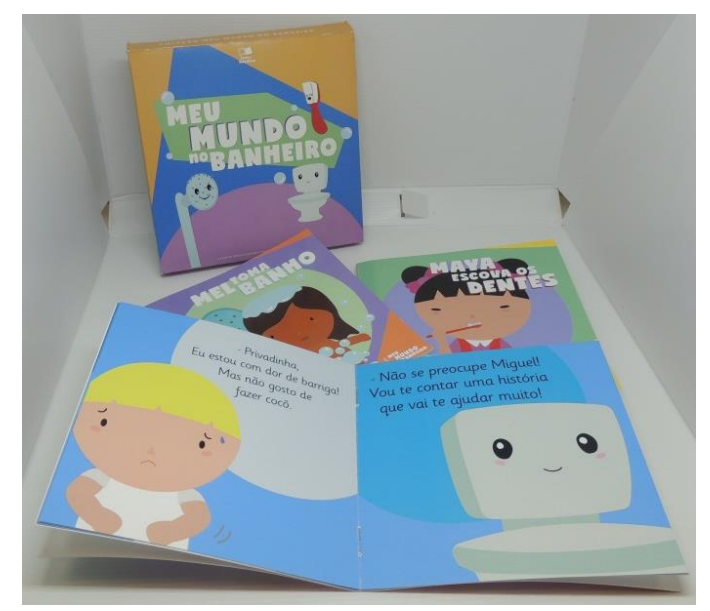

Figura 14 - Meu mundo no banheiro Fonte: SABATINI; VERMÖHLEN (2018)

\section{Livro Um Arco-Íris de Famílias}

O livro Um Arco-Íris de Famílias foi feito para o Núcleo de Desenvolvimento Infantil NDI-UFSC e trata-se de um material que visa mostrar às crianças uma história com as diferentes constituições familiares de uma forma lúdica por meio da representação de animais, facilitando o 
entendimento da criança e auxiliando o professor a abordar temas contemporâneos ligados às diferenças, sejam elas familiares, étnicas ou de gênero. A figura 15 mostra o livro.
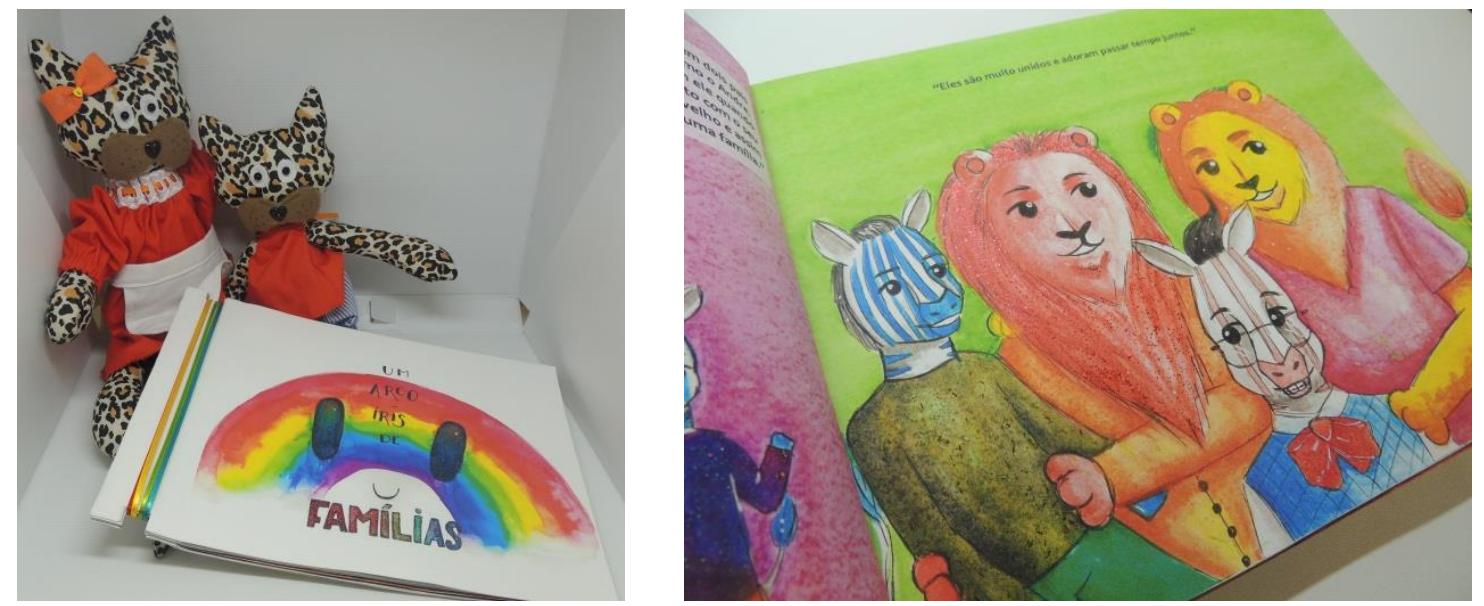

Figura 15 - Um Arco-Íris de Famílias

Fonte: RUSSO; BORDIN; CAZELLI (2018)

\section{Fazendinha Didática}

A fazendinha foi feita para crianças de 4 e 5 anos com base na pesquisa na CEI Frei Ático de São Pedro de Alcântara. O jogo é um tabuleiro direcionado à alfabetização por meio da associação de letra e objetos, facilitando a relação do concreto com o abstrato dos símbolos do alfabeto. A figura 16 mostra o jogo a fazendinha didática.

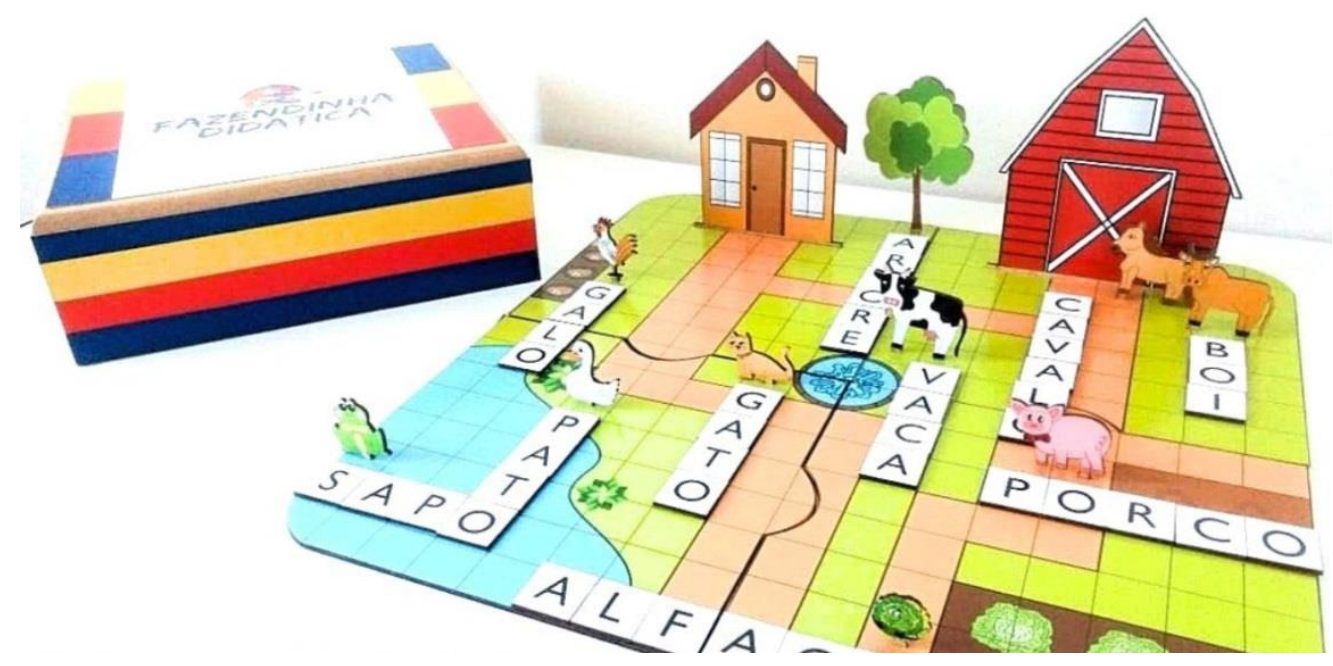

Figura 16 - Fazendinha didática Fonte: SILVA; SOUZA (2018)

Cabe salientar que o cenário pode ser alterado para outros temas e que o jogo é opensource, ou seja, aberto. O termo se aplica a variados trabalhos criativos, como criações artísticas colaborativas, textos, músicas, fotografias e filmes, por exemplo. Esses trabalhos ficam protegidos por tipos variados de licenças que permitem o compartilhamento, cópia ou 
manipulação do conteúdo sem as restrições do "todos os direitos reservados". Neste projeto, ele está disponível em arquivo pdf e podem ser abaixados os desenhos das peças e cortados em qualquer laboratório Fab Lab. Estes laboratórios contam com uma infra-estrutura preparada para realizar diversos projetos de fabricação digital e tecnológica. Existem três tipos de Fab Labs: os acadêmicos, os públicos e os profissionais. Os acadêmicos, sustentados por universidades ou escolas, enquanto os públicos podem ser sustentados por governos, institutos de desenvolvimento ou mesmo comunidades locais. Os Fab Labs profissionais geralmente são os únicos que alugam o espaço ou máquinas, cobrando dos usuários taxas por hora, dias ou meses de uso.

\section{Para aprender: a história do vestido de algodão}

Livro infantil para crianças de 6 anos. O livro conta sobre a origem do algodão e os impactos sociais e ambientais na confecção de roupas, visa sensibilizar crianças a partir de seis anos de idade para o reuso e valorização de vestuários na confecção de um novo produto. O livro incentiva que crianças criem roupas para suas bonecas por meio do reuso de roupas que foram descartadas, o livro tem a sugestão de um molde. A oficina foi feita na creche São Francisco de Assis. A oficina pode ser realizada em qualquer creche e com crianças de qualquer classe social. A figura 17 mostra o livro e na figura 18 crianças com as bonecas durante a oficina oferecida pela aluna.
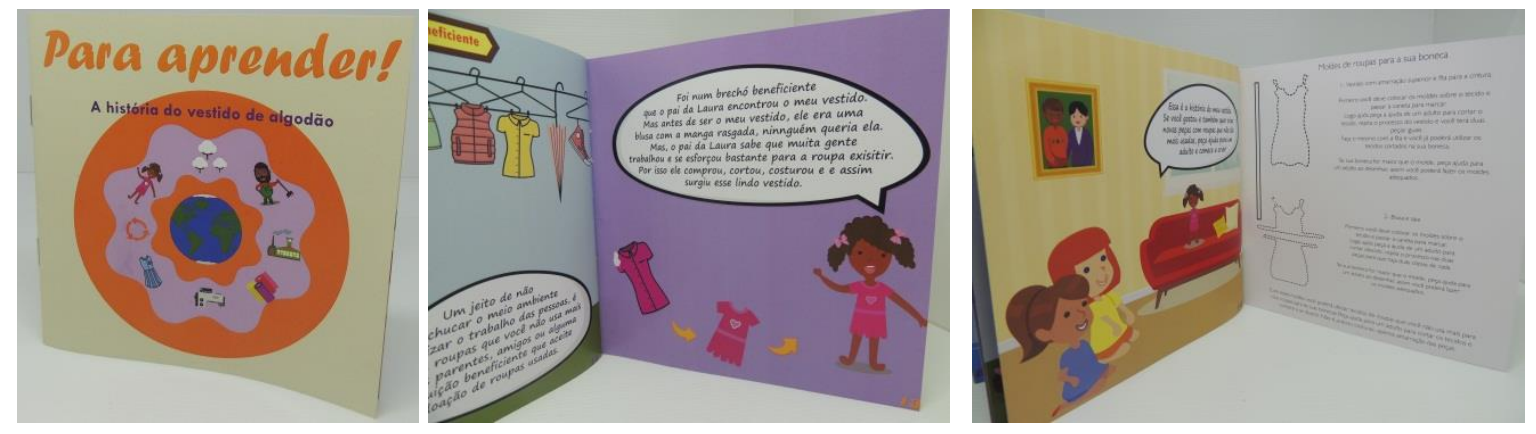

Figura 17 - Para aprender: A história do vestido de algodão Fonte: TOMÉ (2018) 


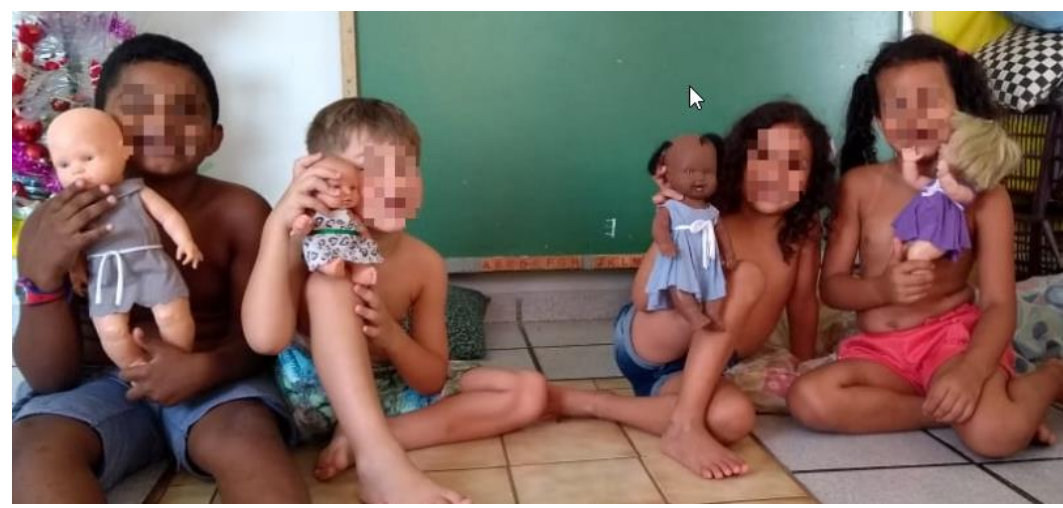

Figura 18 - Crianças na oficina de confecção de roupa de boneca Fonte: TOMÉ (2018)

\section{As aventuras artísticas de Sam}

É um Kit que contem um livro que conta as aventuras de Sam. Cada capítulo tem atividades para a criança colorir desenhar, o kit visa à educação e aprendizagem, ensinando a criança sobre cada material que ela irá utilizar e motivando-a a fazer suas próprias criações artísticas com os mais diversos materiais, como lápis colorido, tinta guache, lápis grafite, biscuit e pedaços de papeis coloridos. As pesquisas foram feitas na escola E.B Adotiva Liberato Valentim. A figura 19 mostra o Kit, uma página e a criança utilizando o material.
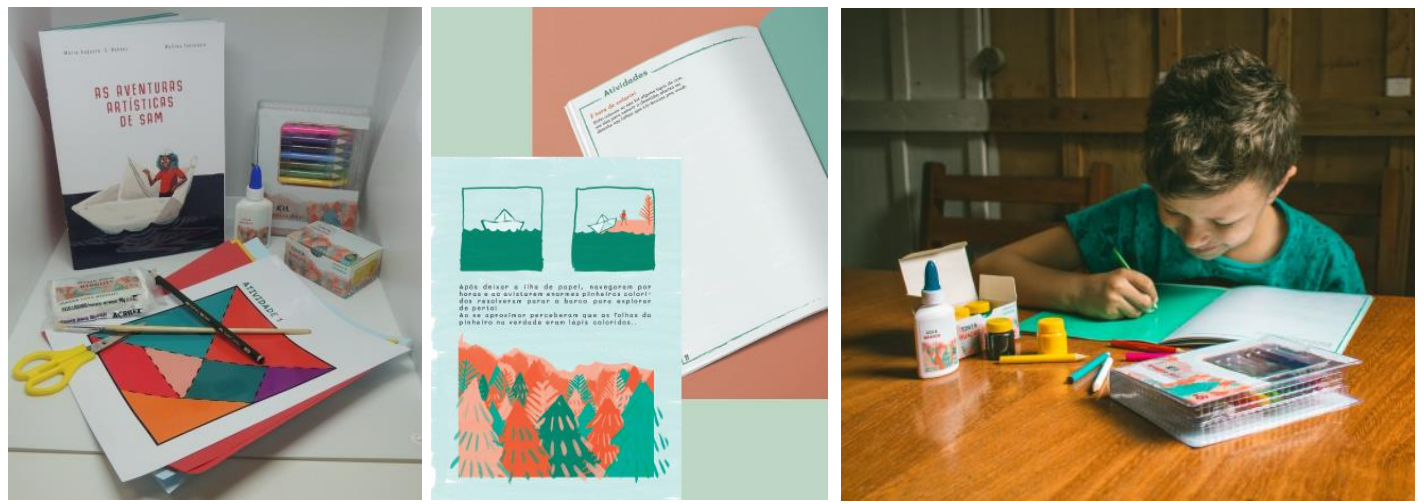

Figura 19 - As aventuras artísticas de Sam Fonte: BOHNER; FONTANELA (2018)

\section{Quanto é? Quiz de Matemática}

Trata- se de um jogo de perguntas e respostas sobre matemática, onde o foco principal é que o aluno possa aprender de uma forma mais divertida, sem a pressão que o ensino de matemática convencional pode causar. Por se tratar de um jogo que é jogado em grupo, consequentemente exige a cooperação de todos os participantes e acaba por gerar uma maior interação e respeito entre a turma. Um total de 150 cartas de perguntas, divididas por 6 cores que representam seis categorias: Cartas roxas - Porcentagem; Cartas laranjas - Fração; Cartas azuis: Adição e subtração; Cartas verdes: Divisão e multiplicação; Cartas pretas: Enigmas e 25 cartas 
vermelhas: Bônus. A pesquisa foi feita com alunos do $5^{\circ}$ ano da Escola Básica Municipal Henrique Veras, situada no bairro da Lagoa da Conceição. A figura 20 mostra o jogo que foi entregue na escola.

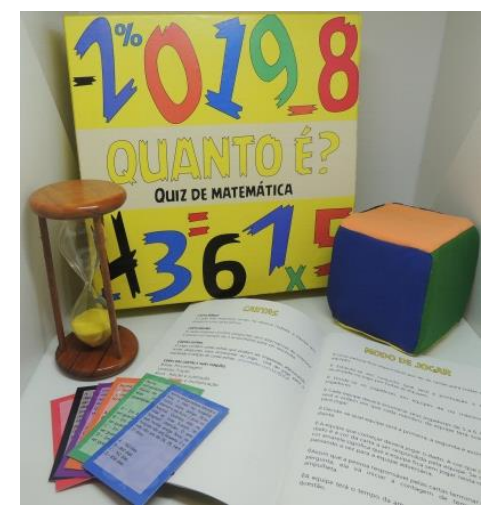

Figura 21 - Quanto é?

Fonte: TOSSEDO; SANTOS (2018)

\section{Play jogo de tabuleiro}

O jogo de tabuleiro Play é para o CASE Centro de Atendimento Socioeducativo de Florianópolis. É um jogo de perguntas e respostas que visa auxiliar ao professor nas aulas de matemática, linguagem, ciências da natureza, ciências humanas, artes e conhecimentos gerais. $\mathrm{O}$ jogo tem uma linguagem gráfica de grafite de forma que os adolescentes se sintam interessados em jogar e aprender de forma divertida. O professor pode criar mais cartas e fazer mais perguntas. A figura 21 mostra o jogo play.

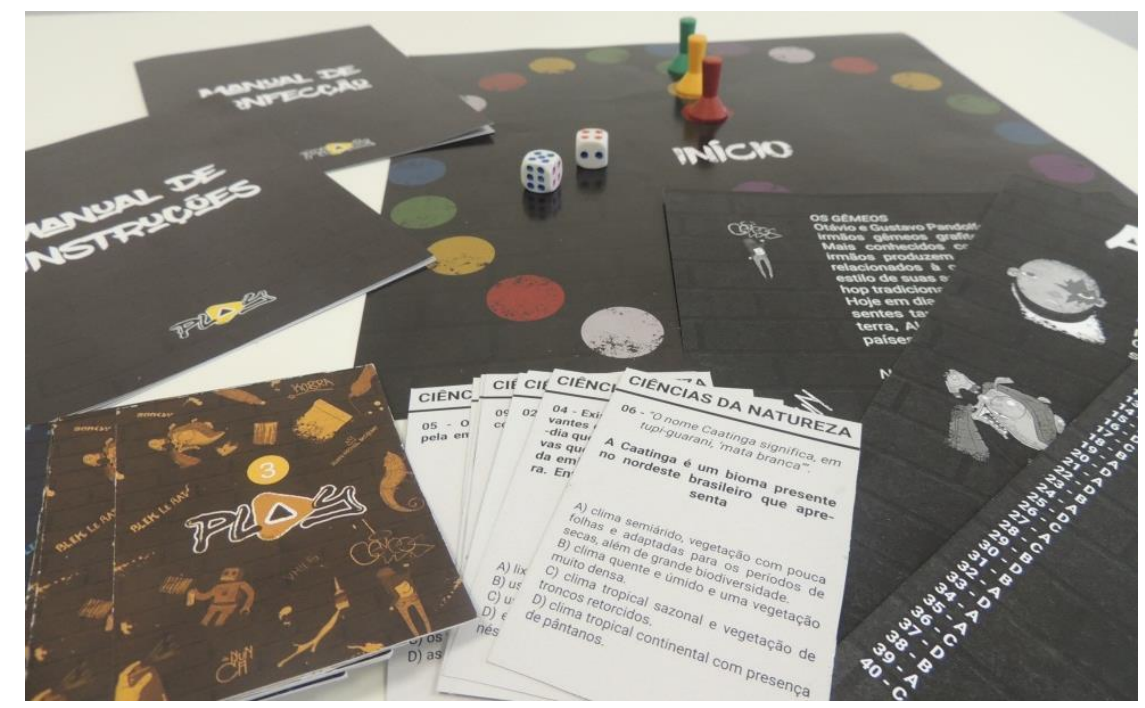

Figura 21 - Play

Fonte: ARMONDES; GOMES (2018) 


\section{Quebra-cabeça 3D: 14 Bis- Ford 1892 - Spunik 2}

O quebra-cabeça 3D foi desenvolvido para o CASE Centro de atendimento socioeducativo de Florianópolis. O jogo visa entreter os adolescentes por meio de um desafio que é progressivo. O quebra-cabeça não tem manual, então a montagem embora seja intuitiva demanda concentração e foco para montar três grandes inovações: o avião 14 Bis (45 peças); foguete Spunik 2 (125 peças) e o Carro Ford 1892 (222 peças). Os adolescentes devem começar pelo primeiro até o último. Depois, o quebra-cabeça pode ser desmontado ou colado para ficar como decoração. Os jovens poderiam fazer estes objetos para vender, mas seria necessário aplicar uma oficina para ensinar a forma de modelar em software 3D e planificar as peças. A figura 22 mostra o 14 Bis e as embalagens.
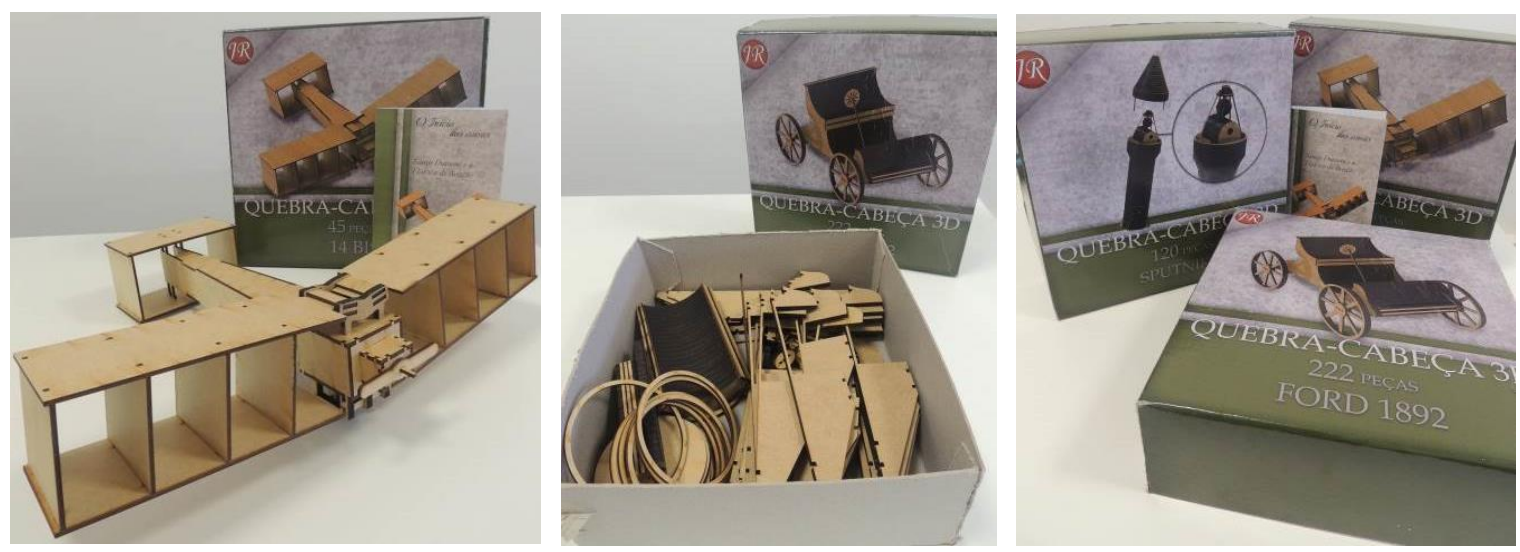

Figura 22 - Quebra-cabeça 3D: 14 Bis- Ford 1892 - Spunik 2 Fonte: REIS; BITTER (2018)

\section{Estante Multifuncional}

A estante multifuncional foi um trabalho de conclusão de curso PCC, feita para o Colégio Primeiros Degraus de São José, trata- se de um mobiliário lúdico que além de ser estante, tem puffs e gavetas. Foi desenvolvido juntamente com as crianças que participaram do desenvolvimento escolhendo a melhor solução e as cores do mobiliário. O modelo foi construído em escala 1:5 e assim que a escola tiver verba será produzido em uma marcenaria. A figura 23 mostra as crianças participando da escolha da estante. 

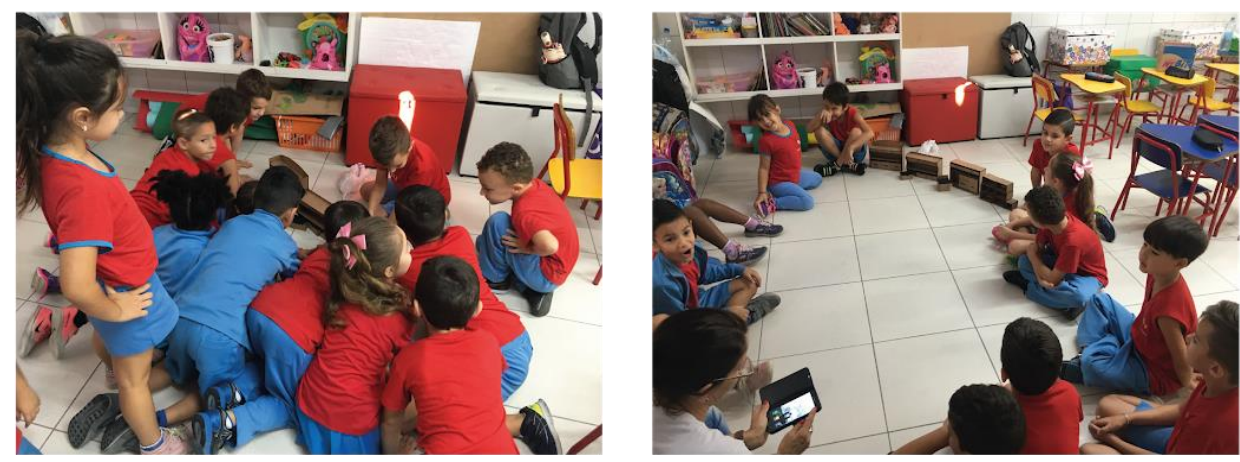

Figura 23 - Teste de modelo da estante na escola Fonte: QUINALIA (2018)

O desenvolvimento da estante foi uma experiência de extensão na comunidade, aplicando a coparticipação das crianças e professores nas tomadas de decisão do projeto.

\section{CONSIDERAÇÕES FINAIS}

A integração do ensino e a extensão por meio da inserção das disciplinas do curso, tanto dos alunos da disciplina de metodologia de projeto que participaram com o tema do projeto se apresenta como uma forma de ação da extensão universitária, possibilitando para que estudantes ultrapassem o espaço da sala de aula para se tornar ação geradora de conhecimento e da vivência cidadã. A participação da aluna de PCC que desenvolveu a estante para a escola, mostra que a extensão universitária acaba contribuindo com a formação do educando por meio de uma ação extensionista. Os bolsistas tiveram a participação ativa nos projetos apresentados assim como auxiliaram os alunos das disciplinas e participaram nas visitas às escolas. Percebe-se pela quantidade de soluções (20) e pelo número de escolas e instituições atendidas (16) que a criatividade e o compromisso do curso de design com a comunidade mostram como o curso pode colaborar com a extensão universitária e o viés social olhando para problemas que o mercado não atende.

Dos resultados dos projetos muitos foram entregues em 2018 e os restantes foram entregues no início das aulas de 2019. Também do projeto formam publicados dois artigos científicos para divulgar a ação de extensão e o potencial do design social. Inserir o design social e a responsabilidade do designer com a sociedade ressignificam o exercício da docência universitária.

A relação de escolas e projetos está no quadro 1. 


\begin{tabular}{|c|c|}
\hline ESCOLAS E OU INSTITUIÇÕES & PROJETOS DESENVOLVIDOS \\
\hline $\begin{array}{l}\text { Escola João Francisco Garcez (escola municipal } \\
\text { de ensino fundamental) no bairro Costa de } \\
\text { Lagoa }\end{array}$ & $\begin{array}{l}\text { 4.3.6 LUME Método criativo escolar } \\
\text { 4.3.9 Banco }\end{array}$ \\
\hline EBB Júlio da Costa Neves & $\begin{array}{l}\text { 4.3.2 GeoJogo } \\
\text { 4.3.7 Chemistory }\end{array}$ \\
\hline Escola Rosinha Campos & 4.3.3 Jogo fauna maluca \\
\hline Creche Nossa Senhora Aparecida & 4.3.1 Recicladuc \\
\hline E.B Adotiva Liberato Valentim & 4.3.16 Kit as aventuras artísticas de Sam \\
\hline EB Vitor Miguel de Souza (carta da Gerência) & 4.3.5 Painéis interativos \\
\hline $\begin{array}{l}\text { APAE (Associação de pais e Amigos dos } \\
\text { Excepcionais) }\end{array}$ & $\begin{array}{l}\text { 4.3.10 Kit pedagógico para TEA (Transtorno } \\
\text { do espectro autista) } \\
\text { 4.3.12 Coleção Meu Mundo no Banheiro }\end{array}$ \\
\hline Creche São Francisco de Assis & $\begin{array}{l}\text { 4.3.15 Para aprender: a história do vestido de } \\
\text { algodão }\end{array}$ \\
\hline $\begin{array}{l}\text { Escola Básica Municipal Henrique } \\
\text { Veras, situada no bairro da Lagoa da Conceição }\end{array}$ & 4.3.17 Quanto é? Quis de matemática \\
\hline $\begin{array}{l}\text { Abrigo Casa Lar AMAR I em São José, Santa } \\
\text { Catarina }\end{array}$ & 4.3.11 Movimente \\
\hline $\begin{array}{l}\text { CASE Centro de atendimento socioeducativo } \\
\text { de Florianópolis }\end{array}$ & $\begin{array}{l}\text { 4.3.18 Jogo de tabuleiro play } \\
\text { 4.3.19 Quebra-cabeça 3D }\end{array}$ \\
\hline $\begin{array}{l}\text { NDI Núcleo de Desenvolvimento Infantil } \\
\text { UFSC }\end{array}$ & 4.3.13 Livro Um Arco-Íris de Famílias \\
\hline $\begin{array}{l}\text { Colégio Primeiros Degraus e São José, Santa } \\
\text { Catarina }\end{array}$ & $\begin{array}{l}\text { 4.3.20 Estante multifuncional para ambiente } \\
\text { infantil para crianças de cinco e seis anos }\end{array}$ \\
\hline $\begin{array}{l}\text { Escola de Educação Básica Vitório Anacleto } \\
\text { Cardoso, de Gaspar/SC e Escola de Educação } \\
\text { Básica João Widemann, de Blumenau/SC. }\end{array}$ & 4.3.8 Cidade matemática \\
\hline CEI Frei Ático (são Pedro de Alcântara) & 4.3.14 Fazendinha didática \\
\hline
\end{tabular}

Quadro 1: escolas e projetos Fonte: da autora

O conjunto de demandas importantes sobre diversos aspectos em creches, pré-escolas, escolas, abrigos, APAE e Centro de atendimento socioeducativo mostram que o design tem um amplo campo de atuação social. A extensão proporcionou para que estudantes vivenciem e se aproximem de outras realidades em instituições diversas como a APAE, Abrigo e Centro de atendimento socioeducativo. Os resultados foram bem recebidos pelas escolas mostrando serem materiais de qualidade, baixo custo e adequados para o grupo de indivíduos que vão utilizar os mesmos.

Cabe salientar a participação dos professores e funcionários das escolas e instituições, alunos do curso de Design e Design de Produto, a Gerência de Educação Continuada - GEC da Secretaria Municipal de Educação da Prefeitura Municipal de Florianópolis e agradecer a Proex UFSC por bolsas para a realização do projeto. 


\section{REFERÊNCIAS}

ARMONDES, Erichk; GOMES, Haneline. Play jogo de tabuleiro. Relatório de projeto de metodologia de projeto do Curso de design UFSC. 2018.

BELMONTE, Carolina; MARTINS, Glaucia. RECICLEDUC. Relatório de projeto de metodologia de projeto do Curso de design UFSC. 2017.

BOHNER, Maria Augusta Scopel; FONTANELA, Wyllian. As aventuras artísticas de Sam. Relatório de projeto de metodologia de projeto do Curso de design UFSC. 2018.

BRUINI, Eliane Da Costa. "Educação no Brasil"; Brasil Escola. Disponível em http://brasilescola.uol.com.br/educacao/educacao-no-brasil.htm. Acesso em 15 de outubro de 2016.

CAPRA, Fritjof; LUISI, Pier Luigi. A visão sistêmica da vida: Uma concepção unificada e suas implicações filosóficas, políticas, sociais e econômicas. São Paulo: Cultrix, 2014.

CORTELLA, Mario Sergio. A escola e o conhecimento: fundamentos epistemológicos e políticos. 15ed. - São Paulo: Cortez, 2016.

Criativos da Escola. Disponível em: http://criativosdaescola.com.br/. Acesso em 22 de Setembro de 2016.

DESIGN THINKING PARA EDUCADORES. O que é design Thinking? Disponível em: http://www.dtparaeducadores.org.br/site/. Acesso em 12 de julho de 2017.

ESCOLA DE DESIGN THINKING. E-book Inovação Social. E-book.

FONTOURA, A. M. Edade: a educação de crianças e adolescentes através do design. Tese de Doutorado em Engenharia de Produção. Universidade Federal de Santa Catarina, Florianópolis 002 .

FRANCO, Mariana; GUERRA, Paola. O contador de histórias. Relatório de projeto de metodologia de projeto do Curso de design UFSC. 2017.

FREIRE, Paulo Reglus Neves. Educação atualidade brasileira. 3 ed. - São Paulo: Cortez: Instituto Paulo Freire, 2003.

GUEDES, Caroline Lengert. A Educação através do design: Desenvolvimento de um projeto cooperativo com recursos da Informática. Dissertação de Mestrado em Engenharia de Produção. Universidade Federal de Santa Catarina, Florianópolis 2002.

GUEDES, Caroline Lengert. Trabalhando com design no ensino fundamental. In: II Congresso Internacional de Pesquisa em Design, Rio de Janeiro - RJ, 2003.

INSTITUTO EDUCADIGITAL. Design Thinking para Educadores. E-book. Disponível em: https://designthinkingforeducators.com/DT_Livro_COMPLETO_001a090.pd. Acesso em 15 de junho de 2017. 
KARKLING, Gabriela; CHICARELLI, Gabriela. Lume: Método criativo escolar. Relatório de projeto de metodologia de projeto do Curso de design de produto UFSC. 2017.

KUMAGAI, Deborah; TOMAZZIA, Pâmela. Chemistory. Relatório de projeto de metodologia de projeto do Curso de design de Produto. UFSC. 2017.

PAIM, Pedro Henrique; JESUS, Vanessa Regina De. Painéis interativos. Relatório de projeto de metodologia de projeto do Curso de design UFSC. 2018.

PERRENOUD, Philippe. Construir as competências desde a escola. Porto alegre: Artes Médicas Sul, 1999.

PERRENOUD, Philippe. Dez novas competências para ensinar. Porto alegre: Artes Médicas Sul, 2000.

PINK, Daniel H. A revolução do lado direito do cérebro: as seis novas aptidões indispensáveis para a realização profissional e pessoal. Rio de Janeiro: Elsevier, 2005.

Prefeitura de Florianópolis Legislação: Leis e Orientações - DEI Orientações Legais

Normatizadores para o Funcionamento da Educação Infantil

http://www.pmf.sc.gov.br/entidades/educa/index.php?cms=legislacao ++ leis + e + orientacoes + ++ dei\&menu=8. Acesso em 15 de junho de 2017.

QUINALIA, Marcella Schneider Vianna. Estante multifuncional para ambiente infantil para crianças de cinco e seis anos. Projeto de Conclusão do curso de Design UFSC. 2018

REIS, João Matheus Cardoso; BITTER, Ricardo Oliveira. Quebra-cabeça 3D: 14 Bis - Ford 1892 - Spunik 2. Relatório de projeto de metodologia de projeto do Curso de design de Produto UFSC. 2018.

RUSSO, Bianca Monguilhott Agriel; BORDIN, Laine; CAZELLI, Paula Petrelli. Livro Um ArcoÍris de Famílias. Relatório de projeto de metodologia de projeto do Curso de design. UFSC. 2018.

SABATINI; Leonardo Melim; VERMÖHLEN, Leonardo. Coleção Meu mundo no banheiro. Relatório de projeto de metodologia de projeto do Curso de design. UFSC. 2018.

SAVALL, Ana Júlia; ALVES, Thainá. Kit pedagógico para TEA. Relatório de projeto de metodologia de projeto do Curso de design de Produto. UFSC. 2018.

SED Secretaria do Estado de Santa Catarina. Disponível em www.sed.sc.gov.br/ acesso em 10 de julho de 2007.

SILVA, Helen Dos Santos Da; SOUZA, Manuella Silva E. Fazendinha Didática. Relatório de projeto de metodologia de projeto do Curso de design de Produto. UFSC. 2018.

SOUZA, Adriel; WERNER, Eduarda. Cidade da matemática. Relatório de projeto de metodologia de projeto do Curso de design de Produto. UFSC. 2017.

SUPTITZ, Ariely Cauany; MEDINA, Maressa Vieira. Movimente. Relatório de projeto de metodologia de projeto do Curso de design de Produto. UFSC. 2018. 
Design Social: desenvolvimento de material didático para Educação Básica

TILLMANN, Ana Julia; ECKSCHMIDT, Melanie. Banco-Baú. Relatório de projeto de metodologia de projeto. Curso de design de Produto. UFSC. 2017.

TOMÉ, Jessica Maria. Para aprender: a história do vestido de algodão. Relatório de projeto de metodologia de projeto do Curso de design de Produto. UFSC. 2018.

TOSSEDO, Ingrid; SANTOS, Musa. Quanto é? Quiz de matemática. Relatório de projeto de metodologia de projeto do Curso de design. UFSC. 2018.

WIENER, Luciana; SELL, Luiza. GEOJOGO. Relatório de projeto de metodologia de projeto do Curso de design UFSC. 2017.

Recebido em: 24/01/2019

Aceito em: 20/08/2019 